\title{
Human thymic stromal lymphopoietin promotes the proliferation and invasion of cervical cancer cells by downregulating microRNA-132 expression
}

\author{
WEN-JIE ZHOU $^{1 *}$, HUI-LI YANG ${ }^{1 *}$, KAI-KAI CHANG ${ }^{1}$, YI MENG ${ }^{1}$, MING-YAN WANG $^{1}$, \\ MIN-MIN YUAN ${ }^{1}$, MING-QING LI ${ }^{1,2}$ and FENG XIE ${ }^{3}$
}

${ }^{1}$ Laboratory for Reproductive Immunology; ${ }^{2}$ Shanghai Key Laboratory of Female Reproductive Endocrine Related Diseases;

${ }^{3}$ Medical Center of Diagnosis and Treatment for Cervical Diseases, Hospital of Obstetrics and

Gynecology, Fudan University, Shanghai 200011, P.R. China

Received December 12,2016; Accepted September 22, 2017

DOI: $10.3892 / 01.2017 .7260$

\begin{abstract}
Thymic stromal lymphopoietin (TSLP), produced by cervical cancer (CC) cells, promotes angiogenesis, and the recruitment and functional regulation of eosinophils. It has been reported that microRNA (miR)-132 is aberrantly decreased in $\mathrm{CC}$ tissues. However, the function and mechanism of TSLP on the biological behaviors of CC cells is largely unknown. The aim of the present study was to investigate the effect of TSLP on the expression of miR-132 and the proliferation and invasion in vitro of $\mathrm{CC}$ cell lines, namely, HeLa and SiHa cells. The transcrpitional level of miR-132 was analyzed using reverse transcription-quantitative polymerase chaon reaction. The proliferation, invasion, and the expression of proliferation and invasion-related molecules in HeLa and SiHa cells in vitro were evaluated using bromodeoxyuridine cell proliferation, Matrigel invasion assays, flow cytometry and ELISA, respectively. Here, it was revealed that recombinant human TSLP (rhTSLP) downregulated the expression levels of miR-132 in HeLa and SiHa cells, and by contrast, the neutralizing antibodies for TSLP or TSLP receptor (TSLPR) upregulated miR-132 expression levels in $\mathrm{HeLa}$ and $\mathrm{SiHa}$ cells. The overexpression of miR-132 resulted in a lowered proliferation and invasiveness, decreased levels of proliferation-associated molecules marker of proliferation $\mathrm{Ki}-67$ and proliferating cell nuclear antigen, and the decreased production of matrix metalloproteinase (MMP)2 and MMP9
\end{abstract}

Correspondence to: Professor Feng Xie, Medical Center of Diagnosis and Treatment for Cervical Diseases, Hospital of Obstetrics and Gynecology, Fudan University, 419 Fangxie Road, Shanghai 200011, P.R. China

E-mail: ylxiefeng@163.com

*Contributed equally

Key words: thymic stromal lymphopoietin, cervical cancer cells, microRNA-132, proliferation, invasion in HeLa and SiHa cells. Compared with the control group, there was a higher level of proliferation and invasion in HeLa and $\mathrm{SiHa}$ cells following stimulation with rhTSLP. However, these effects induced by rhTSLP were significantly impaired in HeLa and SiHa cells with miR-132 overexpression. The results of the present study indicated that TSLP produced by CC cells downregulated miR-132 expression, and stimulated the proliferation and invasion of $\mathrm{CC}$ cells, thereby further promoting the development of $\mathrm{CC}$.

\section{Introduction}

Cervical cancer (CC) is one of the most common gynecological malignancies with high rates of morbidity (0.001-0.05\%) and mortality (0.0024-0.0175\%), endangering the health and quality of life of women globally (1). Although the decreased incidence of $\mathrm{CC}$ has primarily been attributed to the widespread use of cytological screening, invasive $\mathrm{CC}$ remains an issue regarding the mortality rates of patients with CC. Thus, the elucidation of the molecular pathogenesis of $\mathrm{CC}$ is urgently required. The pathogenesis of $\mathrm{CC}$ remains enigmatic and may be connected with numerous factors, including infection with high-risk human papillomaviruses (HPVs) (2).

Thymic stromal lymphopoietin (TSLP) is primarily produced by stromal cells, epithelial cells, fibroblasts, keratinocytes, basophils and other types of cells, including mast cells, smooth muscle cells, fibroblasts, dendritic cells, trophoblasts, and cancer or cancer-associated cells (3-5). TSLP may trigger helper T-cell 2 cytokines, and is associated with airway inflammatory disease, immunoglobulin E production, allergic responses and eosinophilia $(3,4,6)$. The TSLP receptor (TSLPR) is a typical heterodimeric cytokine receptor, including a TSLP binding subunit (TSLPR $\alpha$ ) and $\alpha$-subunit of the interleukin-7 receptor $(7,8)$. A previous study reported that an aberrantly high level of TSLP present in cancer lesions, potentially mediated by hypoxia, was a notable regulator of the progression of $\mathrm{CC}$ by recruiting and licensing tumor-associated eosinophils (EOS) to CC lesions (9). In addition, TSLP produced by CC cells promotes angiogenesis in an EOS-dependent and -independent manner $(10,11)$. Watanabe et al (12) reported that high 
TSLP expression levels indicate a poor prognosis in patients with gastric cancer. However, whether and how TSLP regulates the proliferation and invasion of $\mathrm{CC}$ cells remains unknown.

Previously, an increasing number of studies have focused on the effect of microRNA (miRNA/miR) on CC (13). Zhao et al (14) reported that miR-132 expression was decreased in $\mathrm{CC}$ tissues compared with that in adjacent non-cancerous tissues. Transforming growth factor (TGF)- $\beta$ is a multifunctional cytokine and may induce numerous important signaling pathways in several types of cancer cells $(15,16)$. Furthermore, TGF- $\beta$ may regulate the expression of TSLP in the intervertebral disc tissue (17) and regulate the expression of miR-132 in glioma cells (18). However, it remains unknown whether TSLP regulates the biological behaviors by modulating the expression of miR-132 in CC.

Therefore, the present study investigated the effect of TSLP on the expression of miR-132, and the proliferation and invasion of the CC HeLa and SiHa cell lines in vitro.

\section{Materials and methods}

Cell culture. Cervical epidermal carcinoma HeLa and SiHa cells were obtained from the Institute of Biochemistry and Cell Biology of the Chinese Academy of Sciences (Shanghai, China), and grown in RPMI-1640 medium (Gibco; Thermo Fisher Scientific, Inc., Waltham, MA, USA) supplemented with 5\% fetal bovine serum (FBS; Hyclone; GE Healthcare Life Sciences, Logan, UT, USA) at $37^{\circ} \mathrm{C}$ in a humidified atmosphere containing $5 \% \mathrm{CO}_{2}$.

Reverse transcription-quantitative polymerase chain reaction $(R T-q P C R)$. Following treatment with a range of concentrations of recombinant human TSLP (rhTSLP; 1, 10, $100 \mathrm{ng} / \mathrm{ml}$; R\&D Systems, Inc., Minneapolis, MN, USA), the anti-human TSLP neutralizing antibodies ( $\alpha$-TSLP) or anti-human TSLPR neutralizing antibodies ( $\alpha$-TSLPR) $(5 \mu \mathrm{g} / \mathrm{ml}$; R\&D Systems, Inc.) at $37^{\circ} \mathrm{C}$ in a humidified incubator containing $5 \% \mathrm{CO}_{2}$ for $48 \mathrm{~h}$, with $1 \%$ PBS used as a control. RT-qPCR was performed in order to determine the expression levels of miR-132 in the HeLa and SiHa cells. Total RNA was extracted from these cells using TRIzol reagent (Invitrogen; Thermo Fisher Scientific, Inc.) following the manufacturer's protocol. The total miRNA of HeLa and SiHa cells were harvested using the PureLink ${ }^{\mathrm{TM}}$ miRNA Isolation kit (Invitrogen; Thermo Fisher Scientific, Inc.) according to the manufacturer's protocol. miR-132 expression was detected using the TaqMan MicroRNA Assay kit (Applied Biosystems; Thermo Fisher Scientific, Inc.) according to the manufacturer's protocol. The parameters of the PCR reaction were as follows: $94^{\circ} \mathrm{C}$ for $2 \mathrm{~min}, 1 \mathrm{cycle} ; 94^{\circ} \mathrm{C}$ for $20 \mathrm{sec}, 60^{\circ} \mathrm{C}$ for $34 \mathrm{sec}$ for 40 cycles. The relative expression levels of miR-132 were analyzed using the $2^{-\Delta \Delta \mathrm{Cq}}$ relative quantification method with human U6 small nuclear RNA used as an internal control (19). The sequences of primers and TaqMan probes are presented in Table I. All assays were performed in triplicate.

Overexpression of miR-132 in HeLa and SiHa cells. The miR-132 mimic lentivirus (miR-132-mimic) and its corresponding miRNA lentivirus negative control (miR-NC) were constructed by Shanghai GenePharma Co., Ltd. (Shanghai,
Table I. Sequences of the primers and TaqMan probes.

A, Primer sequence

Gene Sequence (5'-3')

miR-132

Forward TGGATCCCCCCCAGTCCCCGTCCCTCAG

Reverse TGAATTCGGATACCTTGGCCGGGAGGAC

U6

$\begin{array}{ll}\text { Forward } & \text { CTCGCTTCGGCAGCACA } \\ \text { Reverse } & \text { AACGCTTCACGAATTTGCGT }\end{array}$

B, TaqMan probe sequence

Gene $\quad$ Sequence $\left(5^{\prime}-3^{\prime}\right)$

miR-132 FAM-TGGATACGACCGACCAT-BHQ1

U6 FAM-TGCGCAAGGATGACACGCA-BHQ1

miR, microRNA

China). miR-132 overexpression and corresponding control stable cell lines were then established. The recombinant virus was packaged using the Lentivector Expression system (GeneChem Co., Ltd.), and HeLa and SiHa cells were infected. For lentivirus infection, $3 \times 10^{5} \mathrm{HeLa}$ or $\mathrm{SiHa}$ cells were cultured in 6-well plates and incubated for $24 \mathrm{~h}$ prior to be infected. Next, miR-132-mimic lentivirus or miR-NC lentivirus at a multiplicity of infection (MOI) of 20, was added to the cells. After three days, the efficiency of miR-132 overexpression was verified using RT-qPCR analysis. PCR cycling conditions were as follows: $94^{\circ} \mathrm{C}$ for $2 \mathrm{~min}, 1$ cycle; $94^{\circ} \mathrm{C}$ for $20 \mathrm{sec}, 60^{\circ} \mathrm{C}$ for $34 \mathrm{sec}$ for 40 cycles. The subsequent experiments were performed using viruses at the aforementioned MOIs.

Bromodeoxyuridine (BrdU) cell proliferation and Matrigel invasion assays. The miR-NC and miR-132-mimic HeLa and SiHa cells were treated with $\operatorname{rhTSLP}(10 \mathrm{ng} / \mathrm{ml})$ in a humidified incubator containing $5 \% \mathrm{CO}_{2}$ at $37^{\circ} \mathrm{C}$ for 48 or $72 \mathrm{~h}$. In addition, the vehicle (1\% PBS) for the negative control was added. Next, the proliferation ability of the HeLa and SiHa cells was detected using a BrdU cell proliferation assay kit (Merck KGaA, Darmstadt, Germany) according to the manufacturer's protocol. The experiments were performed in triplicate, and repeated 4 times.

In addition, the invasion ability of HeLa and SiHa cells was analyzed using a Matrigel invasion assay. Briefly, the cells inserts (8- $\mu \mathrm{m}$ pore size, $6.5-\mathrm{mm}$ diameter; Corning Incorporated, Corning, NY, USA) coated with $25 \mu$ l Matrigel were placed in a 24-well plate. The miR-NC and miR-132-mimics HeLa and $\mathrm{SiHa}$ cells, at $2 \times 10^{4}$ cells per well, were plated in the upper chamber with $100 \mu 1$ RPMI-1640 medium (Gibco; Thermo Fisher Scientific, Inc.). RhTSLP (10 ng/ml) or the vehicle was added. The lower chamber was filled with $800 \mu 1$ RPMI-1640 medium (Gibco; Thermo Fisher Scientific, Inc.) including $5 \%$ FBS. The cells were then incubated at $37^{\circ} \mathrm{C}$ for $48 \mathrm{~h}$. The 

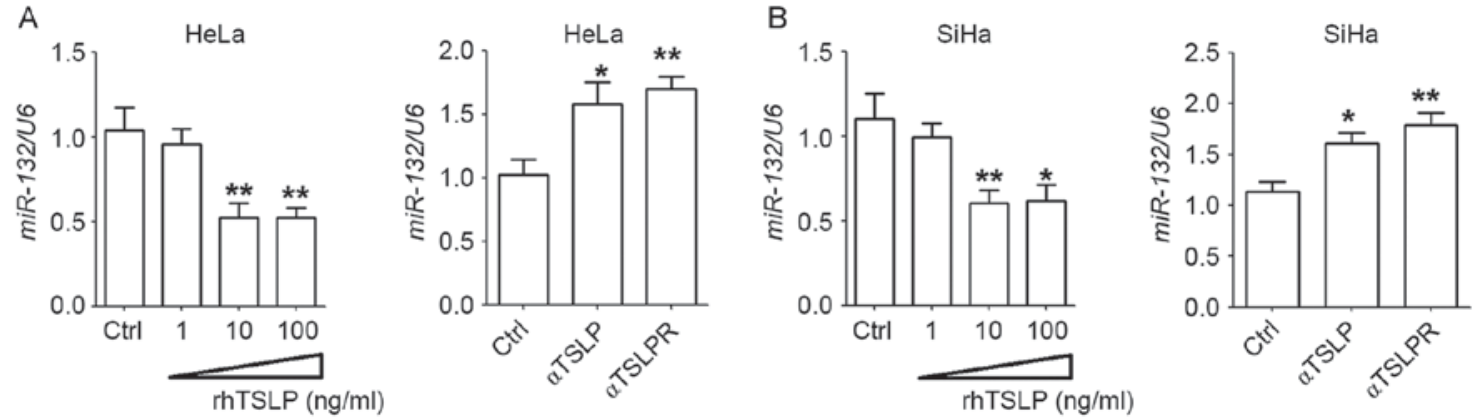

Figure 1. TSLP downregulates the expression levels of miR-132 of HeLa and SiHa cells. Following treatment with differing concentrations of rhTSLP (1, 10 and $100 \mathrm{ng} / \mathrm{ml}), \alpha$-TSLP or $\alpha$-TSLPR ( $5 \mu \mathrm{g} / \mathrm{ml})$, or no treatment for $48 \mathrm{~h}$, the mRNA expression levels of miR-132 in (A) HeLa and (B) SiHa cells were analyzed using reverse transcription-quantitative polymerase chain reaction analysis. ${ }^{*} \mathrm{P}<0.05$ or ${ }^{* * *} \mathrm{P}<0.01$ vs. the control. TSLP, thymic stromal lymphopoietin; rhTSLP, recombinant human TSLP; $\alpha$-TSLP, anti-human TSLP neutralizing antibody; $\alpha$-TSLPR, anti-human TSLP receptor neutralizing antibody; miR, microRNA; Ctrl, control.

inserts were removed, washed in phosphate-buffered saline, and the non-invading cells together with the Matrigel were removed from the upper surface of the filter by wiping with a cotton bud. The inserts were then fixed in methanol for $10 \mathrm{~min}$ at room temperature and stained with hematoxylin for $30 \mathrm{~min}$ at room temperature. The result was observed under an Olympus BX51+P70 microscope (Olympus Corporation, Tokyo, Japan). The cells that migrated to the lower surfaces were counted in 5 predetermined fields using light microscopy at a magnification of $\times 200$. Each experiment was performed in triplicate, and repeated 3 times.

Flow cytometry (FCM). The expression of marker of proliferation Ki-67 and proliferating cell nuclear antigen (PCNA) in HeLa and SiHa cells was analyzed using FCM. Specifically, these cells were fixed with $4 \%$ paraformaldehyde and permeabilized with $70 \%$ ethanol. After centrifugation at $150 \mathrm{x} \mathrm{g}$ for $10 \mathrm{~min}$ at room temperature, the precipitate was resuspended in $1 \mathrm{ml}$ of $0.9 \%$ physiological saline and centrifuged at $150 \mathrm{x} \mathrm{g}$ for $10 \mathrm{~min}$ at room temperature. The precipitate was then resuspended in $150 \mu 10.9 \%$ physiological saline and blocked with human AB serum (Sigma-Aldrich; Merck $\mathrm{KGaA})$ at $4^{\circ} \mathrm{C}$ for $30 \mathrm{~min}$. Samples were then stained with allophycocyanin-conjugated anti-human Ki-67 antibody (1:30, cat. no. 350514; BioLegend, Inc., San Diego, CA, USA) and phycoerythrin-conjugated anti-human PCNA antibody (1:30, cat. no. 307908; BioLegend, Inc.) for $30 \mathrm{~min}$ at room temperature. Thereafter, the cells were washed twice, and resuspended in PBS for FCM analysis. In parallel, APC-conjugated Mouse IgG1, $\kappa$ Isotype Control antibody (1:30, cat. no. 400119; BioLegend, Inc.) and PE-conjugated Mouse IgG2a, $\kappa$ Isotype Control antibody (1:30, cat. no. 400211; BioLegend, Inc.) were used as controls. Samples were analyzed in a FACS Calibur flow cytometer (Becton Dickinson, New York, NY, USA) using Becton Dickinson CellQuest software (version 7.1; Becton Dickinson). Statistical analysis was conducted by using isotype matched controls as references.

Enzyme-linked immunosorbent assay (ELISA). miR-NC and miR-132-mimic HeLa and SiHa cells were cultured in a humidified incubator containing $5 \% \mathrm{CO}_{2}$ at $37^{\circ} \mathrm{C}$ for $72 \mathrm{~h}$. Next, the cell culture supernatant was harvested, centrifuged at $300 \mathrm{x} \mathrm{g}$ at $4^{\circ} \mathrm{C}$ for $10 \mathrm{~min}$ to remove cellular debris, and stored at $-80^{\circ} \mathrm{C}$ until assayed using an ELISA. The secretion level of matrix metalloproteinase (MMP)2 and MMP9 using the supernatant was detected using human MMP2 and MMP9 ELISA kits (Shanghai ExCell Biology, Inc., Shanghai, China) according to the manufacturer's protocols. The experiment was repeated three times.

Statistics. All data are presented as the mean \pm the standard error of the mean. The data were analyzed using GraphPad Prism version 5 (GraphPad Software, Inc., La Jolla, CA, USA) using an unpaired Student's t-test, or one-way analysis of variance followed by Tukey's post hoc test. $\mathrm{P}<0.05$ was considered to indicate a statistically significant difference.

\section{Results}

TSLP downregulates the expression of miR-132 in HeLa and SiHa cells. In order to evaluate the effect of TSLP on the expression of miR-132 in CC cells, HeLa and SiHa cells were treated with with rhTSLP, $\alpha$-TSLP or $\alpha$-TSLPR. rhTSLP was revealed to downregulate the expression of miR-132 in HeLa and SiHa cells, with a signficant difference observed at concentrations of 10 and $100 \mathrm{ng} / \mathrm{ml}(\mathrm{P}<0.05$ or $\mathrm{P}<0.01$; Fig. 1A and B). By contrast, blocking TSLP signaling using $\alpha$-TSLP or $\alpha$-TSLPR significantly upregulated the expression of miR-132 in the HeLa and SiHa cells $(\mathrm{P}<0.05$ or $\mathrm{P}<0.01$; Fig. 1A and $\mathrm{B}$ ). These results indicate that exogenous and endogenous TSLP decrease the expression of miR-132 in CC cells, and may further regulate the biological behaviors of CC cells.

miR-132 inhibits the proliferation and invasion of HeLa and SiHa cells. To investigate the potential function of miR-132 in CC cells, miR-132 was first overexpressed in HeLa and SiHa cells by transfection, and miR-132 overexpression was obtained in miR-132-mimic stable HeLa and $\mathrm{SiHa}$ cell lines, compared with the negative control $(\mathrm{P}<0.001 ;$ Fig. $2 \mathrm{~A})$. Next, it was revealed that there were lower levels of proliferation in the miR-132-overexpressed HeLa and SiHa cells compared with the control cells, with a greater signficant difference observed at $72 \mathrm{~h}(\mathrm{P}<0.05, \mathrm{P}<0.01$ or $\mathrm{P}<0.001$; Fig. 2B $)$. Furthermore, miR-132 overexpression resulted in a lower invasiveness of HeLa and $\mathrm{SiHa}$ cells compared with that of 
A

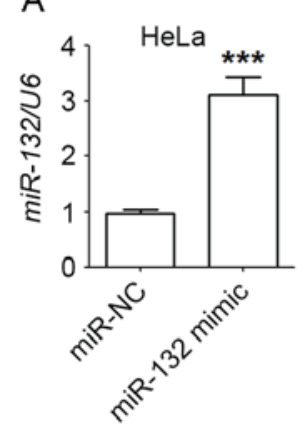

C

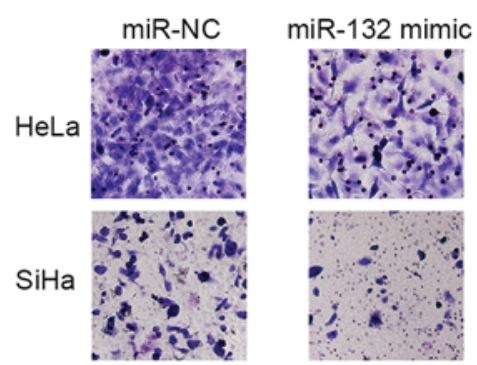

B
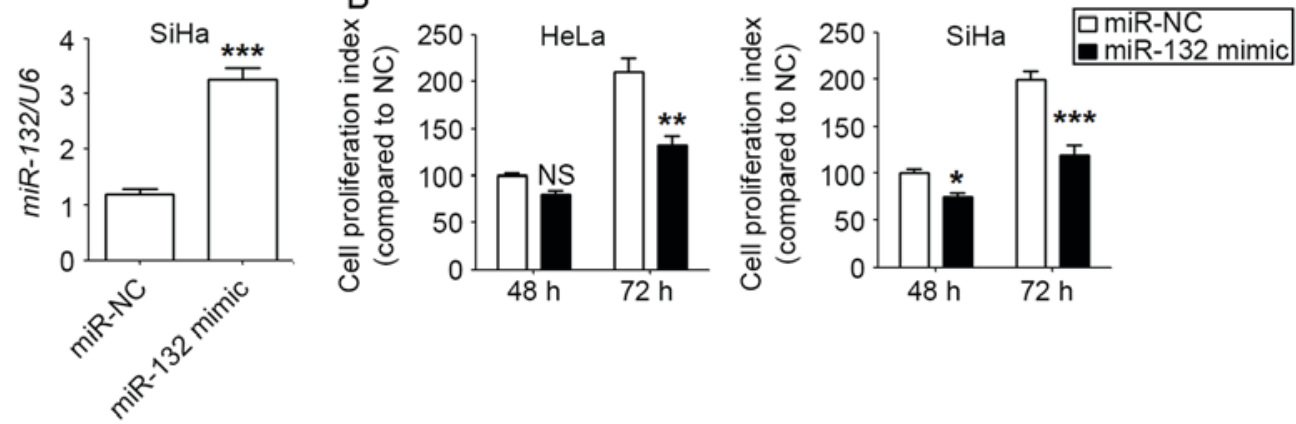

D

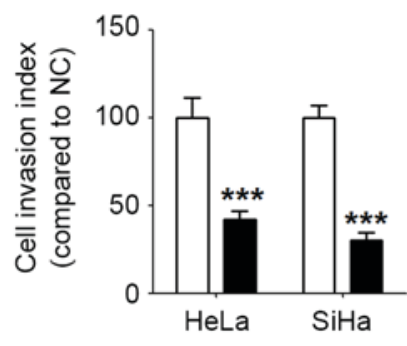

$\square \mathrm{miR}-\mathrm{NC}$

miR-132 mimic

Figure 2. miR-132 inhibits the proliferation and invasion of HeLa and SiHa cells. (A) The overexpression of miR-132 in HeLa and SiHa cells was successfully constructed by transfection, and verified using reverse transcription-quantiative polymerase chain reaction. The (B) proliferation and (C and D) invasiveness of $\mathrm{HeLa}$ and $\mathrm{SiHa}$ cells was analyzed between miR-132-mimic and miR-NC stable HeLa and SiHa cell lines using a bromodeoxyuridine cell proliferation assay for 48 and $72 \mathrm{~h}$, and a Matrigel invasion assay for $48 \mathrm{~h}$, respectively. Original magnification, $\mathrm{x} 200 .{ }^{*} \mathrm{P}<0.05,{ }^{* *} \mathrm{P}<0.01$ or ${ }^{* * * *} \mathrm{P}<0.001$ vs. miR-NC. miR, microRNA; NC, negative control; NS, not significant.

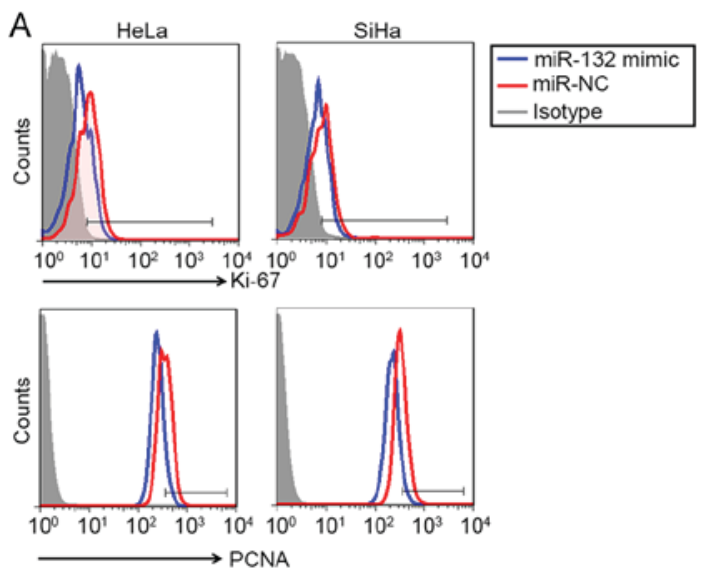

B
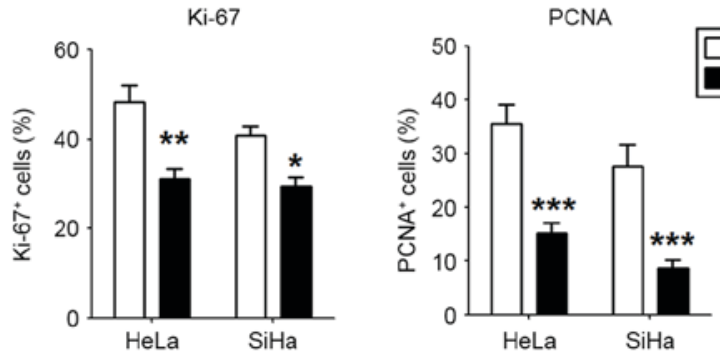

C
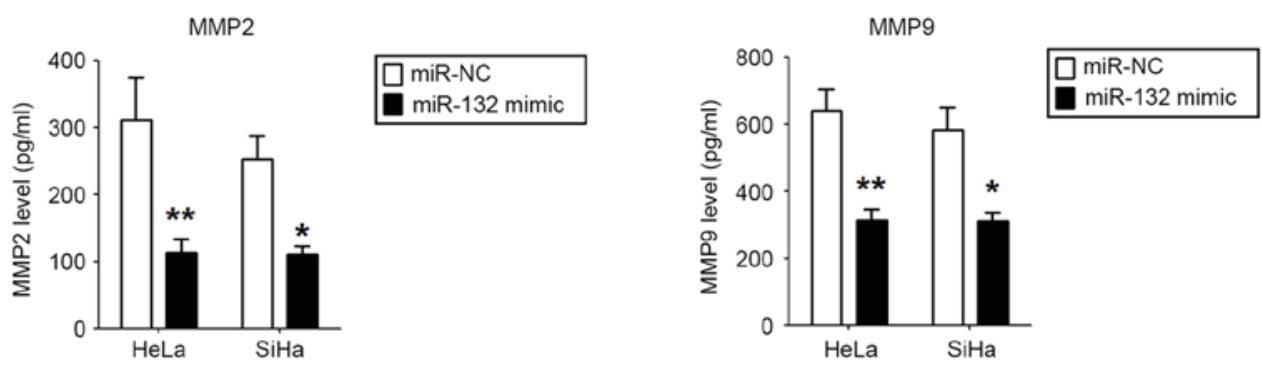

Figure 3. miR-132 downregulates the expression of Ki-67, PCNA, MMP2 and MMP9 of HeLa and SiHa cells. (A) The expression of Ki-67 and PCNA in miR-NC and miR-132-mimic HeLa and SiHa cells was detected using flow cytometry, (B) and quantified. (C) The secretion level of MMP2 and MMP9 of the supernatants of miR-NC and miR-132-mimic HeLa and SiHa cells was analyzed using an ELISA. ${ }^{*} \mathrm{P}<0.05,{ }^{* * *} \mathrm{P}<0.01$ or ${ }^{* * * *} \mathrm{P}<0.001 \mathrm{vs}$. miR-NC. miR, microRNA; Ki-67, marker of proliferation Ki-67; PCNA, proliferating cell nuclear antigen; MMP, matrix metalloproteinase; NC, negative control.

the control cells $(\mathrm{P}<0.001 ;$ Fig. $2 \mathrm{C}$ and $\mathrm{D})$. This data suggest that miR-132 may suppress the proliferation and invasion of CC cells in vitro.
miR-132 downregulates the expression of Ki-67, PCNA, MMP2 and MMP9 in HeLa and SiHa cells. To explore the potential mechanism of miR-132 in regulating the 
A
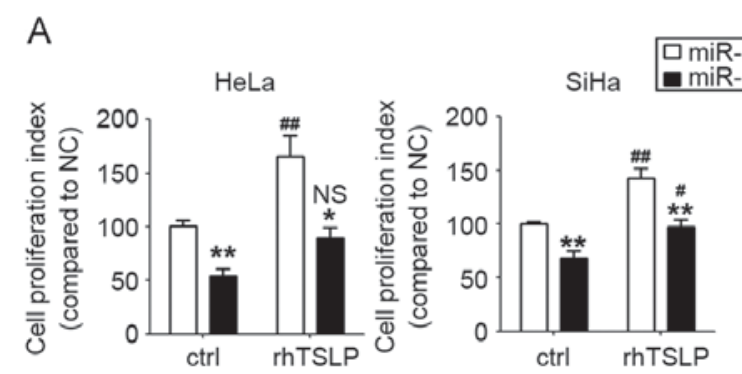

B B

Figure 4. TSLP stimulates the proliferation and invasion of HeLa and SiHa cells via the downregulation of miR-132. The miR-NC and miR-132-mimic HeLa and SiHa cells were treated with or without rhTSLP $(10 \mathrm{ng} / \mathrm{ml})$, and then the proliferation and invasion of these cells were analyzed using (A) a BrdU cell proliferation assay for $72 \mathrm{~h}$ and $(\mathrm{B})$ a Matrigel invasion assay for $48 \mathrm{~h}$. ${ }^{*} \mathrm{P}<0.05,{ }^{* *} \mathrm{P}<0.01$ and ${ }^{* * * *} \mathrm{P}<0.001$ vs. miR-NC. NS, ${ }^{\#} \mathrm{P}<0.05$ or ${ }^{\# \#} \mathrm{P}<0.01 \mathrm{vs}$. the no rhTSLP group. TSLP, thymic stromal lymphopoietin; miR, microRNA; NC, negative control; rhTSLP, recombinant human TSLP; NS, not significant; ctrl, control.

proliferation and invasion of $\mathrm{CC}$ cells, the expression of proliferation-associated molecules Ki-67 and PCNA, and invasion-associated molecules MMP2 and MMP9 were analyzed between miR-132-overexpressed $\mathrm{HeLa}$ and $\mathrm{SiHa}$ cells and control cells. As presented, the overexpression of miR-132 resulted in the significantly lower expression of $\mathrm{Ki}-67$ and PCNA $(\mathrm{P}<0.05, \mathrm{P}<0.01$ or $\mathrm{P}<0.001$; Fig. $3 \mathrm{~A}$ and $\mathrm{B})$, and MMP2 and MMP9 $(\mathrm{P}<0.05$ or $\mathrm{P}<0.01$; Fig. $3 \mathrm{C})$ in the HeLa and $\mathrm{SiHa}$ cells. Together, these data suggest that miR-132 may inhibit the proliferation and invasion of CC cells, potentially via the downregulation of Ki-67, PCNA, MMP2 and MMP9 in vitro.

TSLP stimulates the proliferation and invasion of HeLa and SiHa cells by the downregulation of miR-132. To further explore the function and mechanism of TSLP in CC cells, the miR-132-overexpressed HeLa and SiHa cells and the control cells were incubated with rhTSLP or were left untreated. As presented, rhTSLP markedly stimulated the proliferation and invasion of HeLa and SiHa cells $(\mathrm{P}<0.05$ or $\mathrm{P}<0.01$; Fig. 4A and $\mathrm{B})$. However, the overexpression of miR-132 could partly abrogate the effects of rhTSLP on the proliferation and invasion ability of the HeLa and SiHa cells (Fig. 4A and B). The results of the present study suggest that TSLP promotes the proliferation and invasion of CC cells, and that these effects are partly dependent on the downregulation of miR-132.

\section{Discussion}

As a class of small, highly-conserved non-coding RNAs, miRNAs are known to regulate gene expression at the post-transcriptional level by complementarity with the biding sites in the 3'-untranslated region of the target mRNA (20). It has been reported that miRNAs serve functions in numerous physiological and pathological processes, including cell development, differentiation, proliferation, apoptosis and metastasis. An accumulating body of evidence has indicated that miRNAs serve vital functions in the progression of CC and that they directly contribute to the growth and metastasis of CC cells via the targeting of a large number of critical protein-coding genes. miR-132 is located on human chromosome $17 \mathrm{p} 13.3$, which is associated with various types of human cancer including osteosarcoma, gastric cancer (21), colorectal cancer (22), prostate cancer (23), breast cancer $(24,25)$, hepatocellular carcinoma (26), pancreatic cancer $(27,28)$ and

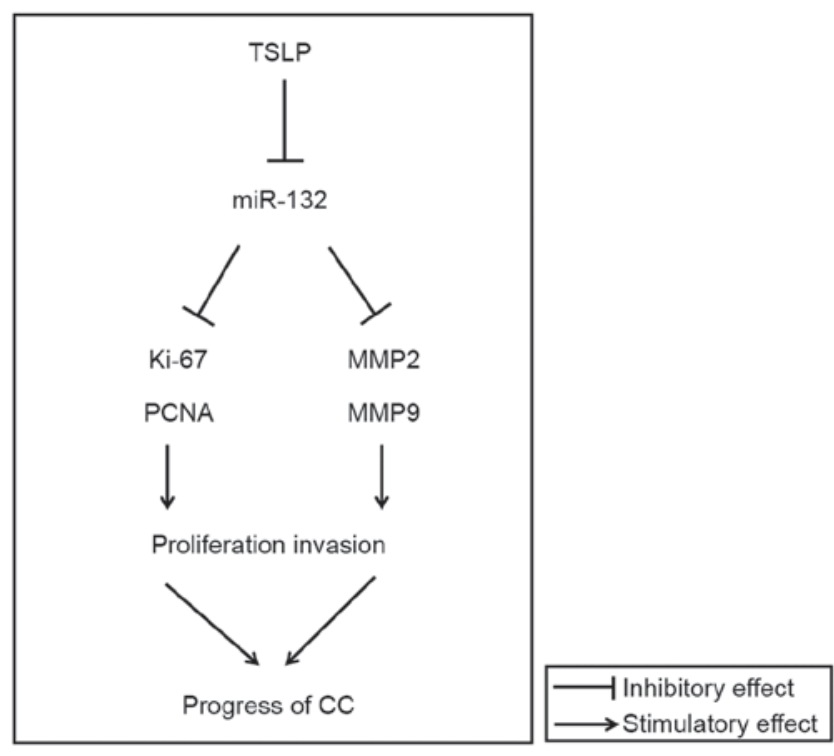

Figure 5. Function of TSLP/miR-132 signaling in CC cells. CC cells secrete high levels of TSLP. TSLP then downregulates the level of miR-132 in CC cells. As a result, miR-132 suppresses the expression of proliferation-associated molecules Ki-67 and PCNA, and invasion-associated molecules MMP2 and MMP9, and further inhibits the proliferation and invasion of CC cells. Therefore, TSLP/miR-132 signaling contributes to the progression of CC. TSLP, thymic stromal lymphopoietin; miR, microRNA; CC, cervial cancer; Ki-67, marker of proliferation Ki-67; PCNA, proliferating cell nuclear antigen; MMP, matrix metalloproteinase.

glioma (29). Zhao et al (14) reported that the expression levels of miR-132 in CC tissues were lower compared with those in adjacent non-cancerous tissues, and it was revealed that miR-132 downregulated SMAD family member (SMAD)2 expression in order to suppress the G1/S phase transition of the cell cycle and the epithelial to mesenchymal transition (EMT) in CC cells. However, the mechanism resulting in the low expression of miR-132 in CC remains largely unknown.

Previous research has established that TSLP is aberrantly highly expressed in CC cells, indirectly promoting their growth by recruiting and regulating tumor-associated EOS, and stimulating angiogenesis in CC lesions (9-11). Additionally, hypoxia may contribute to the increase in the TSLP expression level in CC cells. In the present study, it was revealed that exogenous and endogenous TSLP decreased the level of miR-132 expression in HeLa and SiHa cells, and further stimulated the proliferation and invasion of $\mathrm{CC}$ cells in vitro. In addition, the 
inhibitory effects of miR-132 on the proliferation and invasion of CC cells were associated with the regulation of Ki-67, PCNA, MMP2 and MMP9.

TGF- $\beta$ may upregulate the miR-132 expression level in dose- and time-dependent manners, and may further enhance the activation of TGF- $\beta$ signaling by inhibiting SMAD7 expression in glioma cells (18). TGF- $\beta$ additionally serves important regulatory functions in $\mathrm{CC}$, as for example, the oncoproteins of HPVs may stimulate TGF- $\beta 1$ expression in CC cells, which in turn suppresses the host immune surveillance towards $\mathrm{CC}$, and triggers the EMT process, migration and metastasis of $\mathrm{CC}$ cells (30-33). Endogenous TGF- $\beta$ activity has been reported to limit the expression in of TSLP in intervertebral disc tissue in a steady state by suppressing nuclear factor- $\kappa \mathrm{B}$ activation (17). Therefore, TGF- $\beta$ upregulates the expression of miR-132, potentially by suppressing TSLP production, and the association between TGF- $\beta$, TSLP and miR-132 in CC cells requires further research.

The high level of TSLP production is associated with local hypoxia (9). Notably, hypoxia also results in the upregulation of miR-132 $(34,35)$. Thus, hypoxia may regulate CC cells in a dual-directional manner by upregulating TSLP and miR-132. The precise association and mechanism of hypoxia with TSLP and miR-132 in CC should be further studied for clarification.

Antigen Ki-67 is a nuclear protein that is associated with, and may be necessary for, cellular proliferation. Ki-67 and PCNA are considered to be prognostic markers in CC $(36,37)$. A number of studies have demonstrated that miR-132 inhibits the growth of tumor cells by suppressing the expression of Ki-67 (26,38). Cancer cell migration from the tissue of origin to either the surrounding or distant organs is vital for the progression of tumors. An association has been found between MMP2 and MMP9 and the processes of tumor cell invasion and metastasis in multiple types of human cancer, including uterine neoplasms (39). Jasińska et al (40) reported that miR-132 regulated the structural plasticity of dendritic spines through directly repressing the expression of MMP9. In the present study, miR-132 significantly downregulated the expression of proliferation-associated proteins Ki-67 and PCNA, and invasion-associated enzymes MMP2 and MMP9 in $\mathrm{CC}$ cells, and further suppressed the proliferation and invasion of CC cells in vitro.

Based on the results of the present study and other studies, as presented in Fig. 5, it may be concluded that the high level of TSLP may be attributed to hypoxia and/or TGF- $\beta$. This high level increases EOS infiltration and tumor angiogenesis, and downregulates the expression level of miR-132 in CC cells. miR-132 may decrease the expression of Ki-67, PCNA, MMP2 and MMP9, and limit the proliferation and invasion of CC cells. Therefore, these numerous effects of TSLP contribute to the development of CC. The results of the present study further contribute to the present understanding on the biological function and manner of TSLP/miR-132 signaling in CC progression.

\section{Acknowledgements}

The present study was supported by the National Natural Science Foundation of China (grant nos. 81302260 and 31600735) and the Shanghai Natural Science Foundation (grant no. 17ZR1403200), and the Program for Zhuoxue of Fudan University.

\section{References}

1. Ferlay J, Shin HR, Bray F, Forman D, Mathers C and Parkin DM: Estimates of worldwide burden of cancer in 2008: GLOBOCAN 2008. Int J Cancer 127: 2893-2917, 2010.

2. zur Hausen H: Human papillomaviruses in the pathogenesis of anogenital cancer. Virology 184: 9-13, 1991

3. Liu YJ, Soumelis V, Watanabe N, Ito T, Wang YH, Malefyt Rde W, Omori M, Zhou B and Ziegler SF: TSLP: An epithelial cell cytokine that regulates $\mathrm{T}$ cell differentiation by conditioning dendritic cell maturation. Annual Annu Rev Immunol 25: 193-219, 2007.

4. Sokol CL, Barton GM, Farr AG and Medzhitov R: A mechanism for the initiation of allergen-induced $\mathrm{T}$ helper type 2 responses. Nat Immunol 9: 310-318, 2008.

5. Rochman Y and Leonard WJ: Thymic stromal lymphopoietin: A new cytokine in asthma. Curr Opin Pharmacol 8: 249-254, 2008.

6. Liu YJ: Thymic stromal lymphopoietin and OX40 ligand pathway in the initiation of dendritic cell-mediated allergic inflammation. J Allergy Clin Immunol 120: 238-246, 2007.

7. Park LS, Martin U, Garka K, Gliniak B, Di Santo JP, Muller W, Largaespada DA, Copeland NG, Jenkins NA, Farr AG, et al: Cloning of the murine thymic stromal lymphopoietin (TSLP) receptor: Formation of a functional heteromeric complex requires interleukin 7 receptor. J Exp Med 192: 659-670, 2000.

8. Reche PA, Soumelis V, Gorman DM, Clifford T, Liu Mr, Travis M, Zurawski SM, Johnston J, Liu YJ, Spits H, et al: Human thymic stromal lymphopoietin preferentially stimulates myeloid cells. J Immunol 167: 336-343, 2001.

9. Xie F, Liu LB, Shang WQ, Chang KK, Meng YH, Mei J, Yu JJ, Li DJ and Li MQ: The infiltration and functional regulation of eosinophils induced by TSLP promote the proliferation of cervical cancer cell. Cancer Lett 364: 106-117, 2015.

10. Xie F, Meng YH, Liu LB, Chang KK, Li H, Li MQ and Li DJ: Cervical carcinoma cells stimulate the angiogenesis through TSLP promoting growth and activation of vascular endothelial cells. Am J Reprod Immunol 70: 69-79, 2013.

11. Zhang B, Wei CY, Chang KK, Yu JJ, Zhou WJ, Yang HL, Shao J, Yu JJ, Li MQ and Xie F: TSLP promotes angiogenesis of human umbilical vein endothelial cell by strengthening crosstalk between cervical cancer cells and eosinophils. Oncol Lett: DOI: 10.3892/ol.2017.7121.

12. Watanabe J, Saito H, Miyatani K, Ikeguchi M and Umekita Y: TSLP expression and high serum TSLP level indicate a poor prognosis in gastric cancer patients. Yonago Acta Med 58: $137-143,2015$.

13. Deftereos G, Corrie SR, Feng, Q, Morihara J, Stern J, Hawes SE and Kiviat NB: Expression of mir-21 and mir-143 in cervical specimens ranging from histologically normal through to invasive cervical cancer. PLoS One 6: e28423, 2011.

14. Zhao JL, Zhang L, Guo X, Wang JH, Zhou W, Liu M, Li X and Tang H: miR-212/132 downregulates SMAD2 expression to suppress the G1/S phase transition of the cell cycle and the epithelial to mesenchymal transition in cervical cancer cells. IUBMB Life 67: 380-394, 2015.

15. Miyazono K, Suzuki H and Imamura T: Regulation of TGF-beta signaling and its roles in progression of tumors. Cancer Sci 94: 230-234, 2003.

16. Massagué J: TGF $\beta$ in cancer. Cell 134: 215-230, 2008.

17. Zhu Y, Ohba T, Ando T, Fujita K, Koyama K, Nakamura Y, Katoh R, Haro $\mathrm{H}$ and Nakao A: Endogenous TGF- $\beta$ activity limits TSLP expression in the intervertebral disc tissue by suppressing NF- $\kappa$ B activation. J Orthop Res 31: 1144-1149, 2013.

18. Wang ZH, Zhang QS, Duan YL, Zhang JL, Li GF and Zheng DL: TGF- $\beta$ induced miR-132 enhances the activation of TGF- $\beta$ signaling through inhibiting SMAD7 expression in glioma cells. Biochem Biophys Res Commun 463: 187-192, 2015.

19. Livak KJ and Schmittgen TD: Analysis of relative gene expression data using real-time quantitative PCR and the 2(-Delta Delta C(T)) method. Methods 25: 402-408, 2001.

20. Bartel DP: MicroRNAs: Genomics, biogenesis, mechanism, and function. Cell 116: 281-297, 2004.

21. Liu X, Yu H, Cai H and Wang Y: The expression and clinical significance of miR-132 in gastric cancer patients. Diagn Pathol 9: 57, 2014. 
22. Zheng YB, Luo HP, Shi Q, Hao ZN, Ding Y, Wang QS, Li SB, Xiao GC and Tong SL: miR-132 inhibits colorectal cancer invasion and metastasis via directly targeting ZEB2. World J Gastroenterol 20: 6515-6522, 2014.

23. Formosa A,Lena AM,MarkertEK,CortelliS,MianoR,MaurielloA, Croce N, Vandesompele J, Mestdagh P, Finazzi-Agrò E, et al: DNA methylation silences miR-132 in prostate cancer. Oncogene 32: 127-134, 2013.

24. Zhang ZG, Chen WX, Wu YH, Liang HF and Zhang BX: MiR-132 prohibits proliferation, invasion, migration, and metastasis in breast cancer by targeting HN1. Biochem Biophys Res Commun 454: 109-114, 2014

25. Li S, Meng H, Zhou F, Zhai L, Zhang L, Gu F, Fan Y, Lang R, $\mathrm{Fu} \mathrm{L}, \mathrm{Gu} \mathrm{L}$ and Qi L: MicroRNA-132 is frequently down-regulated in ductal carcinoma in situ (DCIS) of breast and acts as a tumor suppressor by inhibiting cell proliferation. Pathol Res Pract 209: 179-183, 2013.

26. Zhang X, Tang W, Li R, He R, Gan T, Luo Y, Chen G and Rong M: Downregulation of microRNA-132 indicates progression in hepatocellular carcinoma. Exp Ther Med 12: 2095-2101, 2016.

27. Zhang S, Hao J, Xie F, Hu X, Liu C, Tong J, Zhou J, Wu J and Shao C: Downregulation of miR-132 by promoter methylation contributes to pancreatic cancer development. Carcinogenesis 32: $1183-1189,2011$

28. Luo G, Long J, Cui X, Xiao Z, Liu Z, Shi S, Liu L, Liu C, Xu J, Li M and Yu X: Highly lymphatic metastatic pancreatic cancer cells possess stem cell-like properties. Int J Oncol 42: 979-984, 2013.

29. Liu Q, Liao F, Wu H, Cai T, Yang L, Wang ZF and Zou R: Upregulation of miR-132 expression in glioma and its clinical significance. Tumor Biol 35: 12299-12304, 2014

30. Zhu H, Luo H, Shen Z, Hu X, Sun L and Zhu X: Transforming growth factor- $\beta 1$ in carcinogenesis, progression, and therapy in cervical cancer. Tumor Biol 37: 7075-7083, 2016.

31. Sun SH, Liu D, Deng YT, Zhang XX, Wan DY, Xi BX, Huang W, Chen Q, Li MC, Wang MW, et al: SIX1 coordinates with TGF $\beta$ signals to induce epithelial-mesenchymal transition in cervical cancer. Oncol Lett 12: 1271-1278, 2016.
32. Torres-Poveda K, Bahena-Román M, Madrid-González C, Burguete-García AI, Bermúdez-Morales VH, Peralta-Zaragoza O and Madrid-Marina V: Role of IL-10 and TGF- $\beta 1$ in local immunosuppression in HPV-associated cervical neoplasia. World J Clin Oncol 5: 753-763, 2014.

33. Lin H, Huang CC, Ou YC, Huang EY, Changchien CC, Tseng CW, Fu HC, Wu CH, Li CJ and Ma YY: High immunohistochemical expression of TGF- $\beta 1$ predicts a poor prognosis in cervical cancer patients who harbor enriched endoglin microvessel density. Int J Gynecol Pathol 31: 482-489, 2012.

34. Yao C, Shi X, Zhang Z, Zhou S, Qian T, Wang Y, Ding F, Gu X and Yu B: Hypoxia-Induced upregulation of miR-132 promotes schwann cell migration after sciatic nerve injury by targeting PRKAG3. Mol Neurobiol 53: 5129-5139, 2016.

35. Hong S, Lee J, Seo HH, Lee CY, Yoo KJ, Kim SM, Lee S, Hwang $\mathrm{KC}$ and Choi $\mathrm{E}: \mathrm{Na}(+)-\mathrm{Ca}(2+)$ exchanger targeting miR-132 prevents apoptosis of cardiomyocytes under hypoxic condition by suppressing $\mathrm{Ca}(2+)$ overload. Biochem Biophys Res Commun 460: 931-937, 2015.

36. Piri R, Ghaffari A, Azami-Aghdash S, Ali-Akbar YP, Saleh P and Naghavi-Behzad M: Ki-67/MIB-1 as a prognostic marker in cervical cancer-a systematic review with meta-analysis. Asian Pac J Cancer Prev 16: 6997-7002, 2015.

37. Astudillo H, Lopez T, Castillo S, Gariglio P and Benitez L: p53, Bcl-2, PCNA expression, and apoptotic rates during cervical tumorigenesis. Ann N Y Acad Sci 1010: 771-774, 2003.

38. Luo J, Meng C, Tang Y, Zhang S, Wan M, Bi Y and Zhou X: miR-132/212 cluster inhibits the growth of lung cancer xenografts in nude mice. Int J Clin Exp Med 7: 4115-4122, 2014.

39. Libra M, Scalisi A, Vella N, Clementi S, Sorio R, Stivala F, Spandidos DA and Mazzarino C: Uterine cervical carcinoma: Role of matrix metalloproteinases (Review). Int J Oncol 34: 897-903, 2009.

40. Jasińska M, Miłek J, Cymerman IA, Łęski S, Kaczmarek L and Dziembowska M: miR-132 regulates dendritic spine structure by direct targeting of matrix metalloproteinase $9 \mathrm{mRNA}$. Mol Neurobiol 53: 4701-4712, 2016. 